\title{
QUESTÕES SOBRE O ESTILO E SUA RELAÇÃO COM GÊNEROS DO DISCURSO NO PROCESSO DE AQUISIÇÃO DA ESCRITA
}

\author{
MARIA BERNADETE MARQUES ABAURRE \\ MARIA LAURA TRINDADE MAYRINK-SABINSON \\ RAQUEL SALEK FIAD \\ (UNICAMP)
}

\begin{abstract}
This paper presents the theoretical and methodological background which underlies the work conducted over the last decade at IEL/Unicamp by researchers of CNPq project A relevância dos dados singulares para a aquisição da linguagem escrita. The central role attributed to the bakhtinian concept of discourse genres is emphasized, as well as the close relationship between genres and style. Texts representative of two subjects writing acquisition process are presented and discussed as examples of the emergence of style and genre differentiation.
\end{abstract}

O tema deste texto é a questão do estilo individual em sua relação com gêneros discursivos no processo de aquisição da escrita. Antes que passemos a ele, no entanto, julgamos necessário explicitar para o nosso leitor a origem deste tema em nossas preocupações de pesquisa.

Em 1992, propusemos ao CNPq um Projeto Integrado (PI) cujo título era $A$ relevância teórica dos dados singulares para a aquisição da linguagem escrita, tema já implícito em nossos trabalhos individualmente realizados desde a segunda metade da década de 80 , em que adotávamos uma perspectiva de "perplexidade" frente aos dados da escrita, muitas vezes idiossincráticos e misteriosos. O objetivo deste projeto era desenvolver um programa de investigação baseado nos pressupostos do chamado Paradigma Indiciário (Ginzburg, 1986). Passamos a enfatizar a relevância dos dados singulares, episódicos e idiossincráticos, dados estes freqüentemente interpretados como "resíduos" ou "exceções" em abordagens de cunho quantitativo cuja preocupação recai sobre regularidades e tendências gerais (ver, a propósito, Abaurre, 1996, 1999a); Abaurre, Fiad, Mayrink-Sabinson \& Geraldi, 1995; Abaurre, Fiad, Mayrink-Sabinson, 1997).

As produções escritas de crianças, adolescentes e adultos que vínhamos coletando em contextos e situações diferenciadas e sobre as quais vínhamos refletindo, foram reunidas em um Banco de Dados, sediado no Instituto de Estudos da Linguagem da UNICAMP. Este Banco reúne dois corpora longitudinais de sujeitos de classe média, ambos do sexo feminino e filhas de professores universitários, vários corpora tranversais e um conjunto bem amplo de textos escritos por crianças e adolescentes de escolas tanto públicas quanto particulares, de diferentes regiões do país, produzidos em 
diferentes momentos do processo de aquisição da escrita. (ver, a propósito, Abaurre, 1996, 1999a); Abaurre, Fiad, Mayrink-Sabinson \& Geraldi, 1995; Abaurre, Fiad, Mayrink-Sabinson, 1997).

Nossa preocupação centrou-se na discussão da viabilidade de utilizar uma metodologia de caráter indiciário nos estudos da aquisição da linguagem escrita. Preocupamo-nos, principalmente, em estabelecer o que entendíamos como "dados singulares", buscando explicitar critérios de identificação e seleção dos dados a serem tomados como representativos do que se considera "singularidade reveladora" e em discutir a questão do "rigor" metodológico, necessariamente diferente, no âmbito de um paradigma indiciário, do "rigor" entendido no sentido galileano, em paradigmas de investigação centrados nos procedimentos experimentais, na replicabilidade e na quantificação dos resultados (cf. Abaurre, Fiad, Mayrink-Sabinson \& Geraldi, 1995)

Em decorrência da opção metodológica por uma investigação de cunho eminentemente qualitativo, nosso trabalho esteve sempre voltado para a identificação de eventos singulares de escrita que pudessem ser tomados como marcas, como indícios da complexa relação entre o sujeito e a linguagem. Ao sujeito virtual da psicologia, queríamos contrapor os sujeitos reais, as suas histórias particulares e únicas de envolvimento com a linguagem. $\mathrm{O}$ paradigma indiciário de investigação, que privilegia as experiências inferenciais abdutivas e que é fundado no detalhe, no indício, no aparentemente residual, forneceu-nos o quadro ideal para o desenvolvimento de trabalhos a partir dos quais começamos a identificar os contornos de micro-histórias de aquisição da escrita.

Ao lado desta opção metodológica, assumimos uma concepção sócio-histórica de linguagem, vista como lugar de interação humana, de interlocução. Tomada como atividade, como trabalho, a linguagem, ao mesmo tempo que constitui os pólos da subjetividade e da alteridade, é também constantemente modificada pelo sujeito, que sobre ela atua. (Franchi, 1977, 1987).

Foi justamente pelo fato de trabalharmos com base em um paradigma que nos forçava a olhar para o individual, para as escritas idiossincráticas, para as mais diferentes instâncias de manifestação de marcas de subjetividade e por adotarmos a concepção sócio-histórica de linguagem, que passamos a discutir a questão da emergência do estilo ao longo de histórias individuais de aquisição da escrita.

Uma concepção de estilo compatível com a concepção de linguagem adotada e que possibilita refletir sobre a sua emergência, encontra-se em Possenti (1988) que, inspirado em Granger (1968), toma o estilo enquanto escolha e enquanto marca de trabalho do sujeito na linguagem.

Em seu trabalho mais recente, Possenti (2001) defende que a categoria "estilo" deva ser repensada e argumenta que pode ser entendida como um certo modo de organizar uma seqüência (de qualquer extensão), focando-se como fundamental a relação entre essa organização e um determinado efeito de sentido (p.16). Enfatiza a relação entre estilo e escolha - que já havia defendido em 1988 - desta vez colocando-a no interior de uma concepção de língua, de enunciado e de gênero, tais como desenhadas, digamos, pelo menos à moda bakhtiniana (p.16). Deixando mais claro o que entende por escolha, mais adiante em seu texto o autor afirma que pode ser entendida, alternativamente, como efeito de uma multiplicidade de alternativas - 
decorrente de concepções de língua como objetos heterogêneos - diante das quais escolher não é um ato de liberdade, mas o efeito de uma inscrição (seja genérica, seja social, seja discursiva) (pp.16-17).

Fica explicitada, então, a necessidade de se entender escolha junto a uma teoria bakhtiniana de gênero discursivo, o que exclui qualquer possibilidade de se pensar o estilo como desvinculado do gênero em que o sujeito se manifesta.

A concepção de estilo assumida mostrou a existência de vínculos entre estilo, subjetividade e autoria, questões que não podem deixar de ser estudadas com referência à aquisição da escrita e à produção de textos.

A partir da opção feita por focalizar os dados singulares, observamos que certos sujeitos parecem definir preferências em seu trabalho com a linguagem. Assim, a par de escolhas por vezes totalmente idiossincráticas e únicas, que provavelmente jamais se repetirão, os sujeitos dão por vezes indicações de que estão investindo em determinados aspectos, buscando já, a partir de certos tipos de escolhas, provocar algum efeito de sentido em seus interlocutores.

As pesquisas sobre o tema emergência do estilo individual foram desenvolvidas com base, inicialmente, em textos produzidos desde a pré-escola até a última série do ensino fundamental. Cabe destacar aqui que, após um curto período de investigação sobre esse tema, algumas conclusões puderam ser apresentadas a respeito da escrita dos dois sujeitos L.M. e L.M., de cujos corpora longitudinais dispomos no banco de dados, sendo que algumas tendências estilísticas já vinham sendo detectadas antes da análise minuciosa e sistemática empreendida.

No caso da escrita de L.M., por exemplo, Mayrink-Sabinson (1993) já vinha apontando que ela buscava construir, em seus textos iniciais, um efeito de humor. Esse efeito, já nessas primeiras observações, podia ser percebido nos textos produzidos nas quatro primeiras séries, como resultado de um trabalho de linguagem com rimas, ritmo, aliterações, repetições, escolha lexical e de temas engraçados que, principalmente nas duas primeiras séries escolares, parece ser construído via criação de nonsense. Típicos deste período são textos como:

Jurema Jurupinba Jurubeba e Xichariba

Jurema espreme a gema

Jurupinba pinga atoa

Jurubeba linpa a

punda.

e

Xichariba espre a bunda

enquanto pinga o xixi atoua

L.M.

para o [desenho de um coelho] Coelhinho ${ }^{1}$

${ }^{1}$ Respeitou-se, nos exemplos apresentados, a grafia original proposta por L.M. 
Encontrado em uma folha solta de caderno, este, que se poderia considerar um "embrião" de poema, é um exemplar de escrita doméstica, conforme o atesta a dedicatória (para o Coelhinho) que fecha o texto, escrito em 1990, na época de Páscoa, ocasião em que L.M. cursava a segunda série.

L.M. trabalha violando regras e expectativas do leitor, criando um efeito de nonsense. L.M. viola, inclusive, "regras de boas maneiras" ao ousar escrever termos pouco próprios da escrita como bundalpunda e xixi. As escolhas feitas não parecem aleatórias - com elas, L.M. está, ativamente, buscando construir um efeito de humor. Apesar de conhecer muito bem as regras da língua, como a maioria de seus textos mostram, L.M. não as subverte na fala/na escrita a não ser quando quer ser engraçada... Subvertendo a "ordem natural das coisas", inclusive a "ordem", as "regras" da língua, L.M. "cria" humor.

No texto apresentado - como em inúmeros outros - a graça se inicia pela opção mesma de escolher nomes próprios (a letra maiúscula inicial assim indica) engraçados e pouco, ou nada, usuais. O único que se poderia considerar "normal", não sendo, no entanto, comumente utilizado, seria Jurema - L.M. o conheceria das "ervilhas"? - que dá origem por aliteração da sílaba inicial aos dois outros que o seguem, Jurupimba e Jurubeba - este, talvez, eco, no dizer de Bakhtin, de propagandas veiculadas, na época, pela televisão - . Esta escolha de nomes fora do comum/inusitados para personagens de seus textos, mantida como marca estilística de L.M., pode ser observada mesmo nas séries mais avançadas de escolarização, como se poderá ver abaixo.

Quando a análise é estendida às produções escritas dos Ensinos Fundamental e Médio (Mayrink-Sabinson, 2000; 2002, 2003), outros recursos, além dos acima referidos, são repetidamente utilizados, sendo um deles a escolha, em diferentes momentos do processo de aquisição da linguagem escrita, de temas de seu cotidiano, lembrados nos textos provavelmente por violarem o "esperado", "a normalidade", sendo, talvez por isto mesmo, considerados "engraçados" e merecedores de serem narrados por escrito. Distanciando-se dos fatos vividos o sujeito ri de si mesmo e provoca efeito de humor ao relatá-los:

Oos Banheiros de minha vida

Certa vez eu estava num restaurante quando me deu vontade de ir ao banheiro, quando sentei na privada senti uma coiza macia. Olhei pra tras e percebi que o asento tinha uma almofada, e achei muito engasado porque nunca vi um asento de privada com almofada.

Alguns dos banheiros que eu ia eram muito legais porque não tinha tualha para secar as mãos e sim um secador era só apertar um botão que ele funcionava.

Num outro banheiro que eu fui era num motel e o box pra tomar banho era de prástico achei super estranho.

Fui em muitos outros banheiros mais o que mais gosto e sempre vou gostar e o banheiro de avião é todo equipadinho, eu adoro.

Como outros textos, este, uma produção da quarta série, tematiza fatos vividos: lembranças conhecidas através de relatos dos pais, vivências e experiências da própria L.M.. A própria escolha do tema é já curiosa e engraçada. L.M., uma grande "apreciadora" de banheiros, buscando conhecê-los em lojas, restaurantes, casas que visitava etc. e, por esta "mania" motivo de zombaria da família, parece tomar distância 
e rir de si mesma ao optar (podendo escolher qualquer tema, já que se tratava de "texto livre") por escrever sobre Oos banheiros de minha vida. O próprio título soa irônico. E, dos banheiros de sua vida, L.M. escolhe falar do que achou muito esquisito, super estranho, desvendando para o leitor a razão de sua busca por banheiros - matar a curiosidade quanto a uma possível variedade/diferença.

Um outro recurso de construir humor no texto, que surge nos primeiros textos de L.M. e se mantém até o final do ensino médio, é a escolha de características inusitadas/contraditórias/ridículas para construir os personagens e os próprios enredos, bem como a criação, a partir da utilização destes recursos, de enredos/situações narradas inusitadas e "engraçadas". Assumindo a voz de um outro assim construído, L.M. cria humor. Um exemplo é:

5 de Maio - Nunca estive mais feliz. Meu casamento com Marta vai quase as mil maravilhas. O único problema é termos caído na famosa rotina. Acho que devemos viajar para solucionar esse problema, mas isso custa muito caro, o nosso orçamento deixa a idéia inviável por enquanto.

17 de Maio - Minha mulher é brilhante! Encontrou a solução perfeita para o nosso problema. Ela nos matriculou em uma academia! Não acho que estejamos fora de forma, principalmente meus ossos magros, mas se essa é a solução...

18 de Maio - Conheci a nossa nova academia. Seu gerente, apesar do nome um tanto peculiar, como Walmor, é muito simpático e nos trata muito bem.

26 de Maio - Marta está encantada com a academia. Passa horas malhando apesar de eu não poder acompanha-lá sempre. O que me conforta é que o seu Walmor faz companhia a ela. Hoje me disse que ele é um expert em filmes de ação, e me pediu para alugar alguns, apesar de seu gênero preferido ser o Romântico.

30 de Maio - Tenho visto minha mulher cada vez menos. Espero que ela não esteja virando uma ratazana de academia como as jovens de hoje em dia. Preciso ver um médico, estou com uma coceira incrível na testa.

1 de Junho - Péssimo dia. Não vi minha mulher hoje por mais do que duas horas, e meu médico não sabe o que é essa coceira infernal.

2 de Junho - Estou irritado! Minha mulher convidou o exímio gerente para jantar, muito bem arrumado. Que e agora não larga mais a minha mulher. Conclusão: não pude conversar com Marta sobre o andamento de nosso casamento.

5 de Julho - Fui andar de bicicleta para aliviar o estresse e a coceira. Ao voltar para casa tive a desagradável surpresa de encontrar o senhor gerente malhando em cima da minha mulher. Descobri o motivo da coceira, que passou num instante quando pintei na cara de Walmor um belo olho roxo que combinava com suas meias e camisa.

6 de Junho - Não volto mais naquela maldita academia, e quero o divórcio!

Neste texto, escrito no ensino médio, podemos encontrar alguns dos recursos de que L.M. se vale para construir textos bem humorados. Ao assumir a voz do outro (neste caso, sob a forma de uma máscara masculina e de um diário) na composição da personagem que escreve o texto, L.M. joga com contradições na fala da própria personagem: um homem distraído em relação ao que se passa a sua volta, que se sente feliz por um casamento que vai quase as mil maravilhas, sendo o único problema ter caído na famosa rotina, e que só ao encontrar o senhor gerente malhando em cima de minha mulher se dá conta, tendo uma desagradável surpresa, da traição que ele mesmo relata, passo a passo, em seu diário. $\mathrm{O}$ recurso ao lugar comum da coceira incrível na testa (coceira infernal, em outro momento no texto) sinaliza para o leitor a traição em andamento, caracterizando o autor do diário e personagem da história como um marido 
enganado. Como em vários outros textos, L.M. constrói indiretamente, usando as próprias palavras do outro/personagem, as qualidades ou defeitos que lhes são atribuídos.

Resumindo, a tendência de construir textos bem humorados e engraçados continua no Ensino Médio, principalmente nos textos em que L.M. assume uma postura narrativa (mas não exclusivamente neles, como veremos adiante). Isto acontece quando a proposta permite, ou seja, L.M. muitas vezes precisa escrever textos sérios. Os recursos de que ela se vale para construir o humor no texto parecem ser os mesmos utilizados quando cursava a oitava série do Ensino Fundamental, considerando, claro, a complexidade maior dos textos que produz. Um dos mais frequientes desses recursos é trabalhar características "engraçadas" assumindo a voz/a escrita de um outro que se faz personagem/narrador da trama.

Os trabalhos de Abaurre (1999b, 2001, 2003) voltam-se para a busca dos indícios de um estilo individual em construção no corpus longitudinal de M.L., constituído de sua produção escrita escolar e doméstica coletada desde o início de seu interesse pelas atividades de escrita e leitura, em fase pré-escolar, até o seu ingresso em um curso universitário. Os dados que serviram de base para as investigações de Abaurre incluem textos representativos de diferentes gêneros e embriões de gêneros discursivos e permitiram chegar às generalizações que seguem acerca do estilo em construção por esse sujeito.

O primeiro conjunto de textos analisados é representativo das séries iniciais (primeira e segunda) do ensino fundamental, e mostra já o fascínio de M.L. com a construção do sentido. Ela parece dar-se conta da possibilidade de utilizar a linguagem para subverter os sentidos usuais, transgredindo regras semânticas. Alguns dos seus textos procuram criar um efeito de nonsense, para o que recorre, algumas vezes, a um jogo fônico; outras vezes, à subversão da lógica do mundo conhecido. Como espaço privilegiado para o exercício de construção do nonsense, M.L. recorre, com freqüência, nessa fase, a poemas ou embriões de poemas, ou a textos em prosa de gênero indefinido ou que se constituem em embriões de exposições em que o sujeito descreve ou elabora hipóteses sobre situações logicamente absurdas.

Como exemplo dessa fase, veja-se o dado abaixo, produzido por M.L. em 1984, na segunda série do ensino fundamental. Observa-se já, associada ao nonsense intencionalmente construído pelo sujeito, uma sugestão de ironia, introduzida pela conjunção adversativa mas. É sem dúvida irônico afirmar que o portão não possa também pular o cão...: ${ }^{2}$

\footnotetext{
"Rimasinhas"

O cão pula o portão a procura de João! Mas o portão não pula João a procura do cão!

Exsistem 12 canetas e um so lápis, se as dose canetas pulam no lápis o machucam mas se o lápis for para omedico, 12 capsulas de remédio também o machucam
}

\footnotetext{
${ }^{2}$ Em todos os exemplos apresentados neste trabalho, respeitou-se a grafia original proposta por M.L.
} 
Sob o título, "Rimasinhas", agrupam-se dois pequenos textos que podem ser vistos como exemplares embrionários do gênero expositivo. No primeiro deles, temos um exemplo de utilização das rimas (em "ão") já associadas à obtenção de um efeito de nonsense (“...o portão não pula João à procura do cão!") através da inversão da relação agente/objeto (João/portão).

O segundo texto apresenta, inicialmente, um jogo semelhante ao do primeiro pela manutenção da estrutura adversativa e pela retomada dos mesmos termos (lápis/canetas) que se alternam em diferentes posições sintáticas. Ao mesmo tempo que se mantém o nonsense (canetas que pulam em lápis e lápis que vão a médicos), há, aqui, um outro efeito de estranhamento, criado agora no nível semântico, uma vez que aquilo que poderia ser visto como uma solução para o problema (a ida ao médico para a cura dos machucados eventualmente provocados por 12 lápis) passa, ironicamente (pelo excesso: 12 cápsulas de remédio!), a causar o mesmo problema que levaria o lápis a procurar o médico.

O segundo conjunto de textos, produzidos a partir da segunda série e até a quarta série do ensino fundamental, aponta para um movimento estilístico singular, que passa a caracterizar grande parte da produção desse sujeito: a associação de um viés irônico ao jogo lúdico. Nesse momento, o lúdico, associado ao efeito de ironia, passa a desempenhar uma função argumentativa mais sugerida do que explicitada nos textos do sujeito. Através dessa nova perspectiva, o sentido da realidade resulta por vezes, em algumas circunstâncias, questionado e/ou criticado por M.L. Nessa fase, é grande a variedade dos gêneros do discurso explorados pelo sujeito, como suporte para o lúdico já sinalizador de uma ironia que virá a constituir-se em forte marca estilística na maior parte da produção escrita de M.L. a partir desse momento. Assim, ela recorre, dentre outros gêneros, a cartas, panfletos, histórias em quadrinhos. Veja-se o texto abaixo (1985, terceira série, texto produzido em casa):

Carta daqueles que tem uma imaginação fora do comum e que são canhotos, nos reclamamos que [a] maioria das pessoas não tem um pingo de imaginação nos solicitamos a estas pessoas que tenham um pouco de imaginaçao ao menos, e se eles quisessem pensar ao menos um pouquinho, para que essa mania de ficar copiando fosse para o espasso, afinal a gente tem cabeça, não é so para separar as orelhas.ass. L.

Este dado ilustra exemplarmente a visão que tem M.L. do que deve ser reconhecido como criativo: o diferente, o que vai contra a maré, foge às expectativas e ao padrão. Criativo é o canhoto, o gauche. Sua posição, nesse sentido, é tão extremada, que ao final do texto ela recorre à ironia para sugerir que as pessoas desprovidas de imaginação (criatividade) são também desprovidas de cérebro: sua cabeça, vazia, tem como função apenas separar as orelhas!

O terceiro conjunto de textos, representativo da produção escrita de M.L. ao longo do segundo ciclo do ensino fundamental (quinta à oitava série) e das três séries do Ensino Médio, mostra o resgate de uma perspectiva já prenunciada em produções anteriores, agora filtrada pela consciência crítica que demonstra ter o sujeito da realidade social em que vive. Nesse momento, o uso da ironia é intencional e o sujeito a ela recorre em função da argumentação explícita e da construção de uma perspectiva 
analítica. O gênero ao qual recorre com maior freqüência para o exercício argumentativo e analítico passa naturalmente a ser a exposição, desenvolvida predominantemente sob a forma de textos dissertativos. Veja-se, como exemplo, o trecho abaixo, extraído de uma dissertação (1993, terceira série do ensino médio, redação produzida no exame vestibular da Unicamp/94):

Não existem cidadãos famintos

\section{(...)}

O estado existe para garantir aos brasileiros o direito à alimentação, o direito à educação, o direito de poder exercer plenamente seus direitos de cidadão. A campanha contra a fome nasceu da mesma incompetência estatal que gera a miséria. O objetivo principal da campanha contra a fome é justamente resgatar a cidadania, e fazer com que os miseráveis passem a exercer os direitos de cidadão que estavam cada vez mais restritos às elites. A sociedade é capaz de mudar o estado. Por isso a mobilização social incomoda tanto as elites. O estado brasileiro funciona para tirar, e não, garantir os direitos de seus cidadãos. Cada vez mais brasileiros estão abaixo da linha da miséria, e cada vez mais essas elites arcaicas fazem questão de ignorá-los. Criticam a campanha contra a fome, mas não vêem que só tomando-se alguma atitude imediata contra a miséria combate-se o desemprego e a violência. Talvez as elites não percebam que são elas as mais atingidas pela violência que a fome gera. Enquanto as elites se fecham, a miséria evolui. (grifo nosso)

Chama particularmente a atenção a maneira como este texto está estruturado. O uso recorrente de orações coordenadas faz com que o leitor seja forçado a reconstruir as relações semânticas subjacentes à argumentação explicitada. Esse investimento na estrutura sintática, ao mesmo tempo que privilegia a construção de um estilo mais ágil e seco, favorece o teor argumentativo da dissertação na medida em que "transfere" para o leitor a responsabilidade de refazer o percurso analítico que conduziu às conclusões explicitadas. Assim, elevado a uma condição de co-autor do texto, o leitor estará certamente mais predisposto a aceitar o encaminhamento analítico que ali se propõe para o tema a ser desenvolvido.

O recurso sintático utilizado é bastante evidente; é impossível, no entanto, afirmar com segurança que M. L. tenha tido consciência, ao trabalhar com as estruturas de coordenação, do alcance da estratégia utilizada, do ponto de vista retórico. Pode-se dizer, no entanto, sem risco de erro, que foi intencional a criação da ironia, no texto, como recurso argumentativo no âmbito de sua exposição. Nesse sentido, o enunciado que fecha o segundo parágrafo do texto - Enquanto as elites se fecham, a miséria evolui - pode ser tomado como exemplar.

Abaurre conclui assim, nessa etapa da pesquisa, que M.L. começa bem cedo o trabalho para produzir nonsense, principalmente em relatos e narrativas, gêneros propícios para a exploração desse efeito. A partir da $3^{\circ}$ série, a exploração do nonsense fica em segundo plano e os textos de M.L. deixam transparecer a sua preocupação com a temática social, onde há maior exploração de recursos sintáticos.

Além da emergência do que se pode tomar como estilo em termos de marcas de autoria a partir de escolhas preferenciais de um sujeito, definimos como relevante para 
nossa investigação a questão mesma do estilo que se pode tomar como característico de um gênero, porque o singulariza e diferencia com relação aos demais.

Nossas investigações atuais centram-se na análise da relação entre a emergência dos estilos individuais e os estilos dos gêneros em si. Tomamos como pressuposto que os próprios gêneros com os quais os sujeitos entram em contato em vários contextos ao longo do seu processo de aquisição da escrita constituem lugares de manifestação estilística dos autores dos textos. É no interior dos gêneros e em vínculo estreito com seus estilos próprios, que estamos buscando as marcas da emergência dos estilos individuais.

A relação entre gênero discursivo e estilo individual a partir da análise de corpora específicos foi-se tornando uma questão central no Projeto Integrado, em parte devido às características dos próprios corpora analisados - dado que eles se foram constituindo de tal forma que passaram a conter uma amostragem significativa das incursões dos sujeitos, através de suas escritas em construção, por vários gêneros - eles próprios em construção -, e em parte ao fato de que pensar a questão do estilo implica necessariamente refletir sobre a questão da diferenciação estilística própria aos gêneros discursivos.

A teoria em que nos apoiamos para fazer a reflexão sobre gêneros é a de Bakhtin (1992), que defende a idéia de que sempre que utilizamos a linguagem o fazemos através de gêneros do discurso. Ao discutir as relações entre os enunciados e os gêneros do discurso, Bakhtin salienta, de um lado, a individualidade do enunciado (visto como o lugar onde a língua se realiza) e, por outro, a variedade dos gêneros do discurso, que se relacionam às diferentes esferas das atividades humanas. O estilo está ligado ao enunciado e aos gêneros do discurso pois, por um lado, o enunciado é individual, isto é, possui um estilo individual, mas, por outro, nem todos os gêneros do discurso favorecem essa manifestação do individual nos enunciados. $\mathrm{O}$ estilo, entendido como a seleção dos recursos lingüísticos feita a partir das possibilidades oferecidas pela língua, não pode, portanto, ser estudado independentemente do gênero do discurso. Finalmente, tanto a escolha dos gêneros como a escolha do estilo do enunciado (ou seja, dos recursos lingüísticos) são decorrência da assunção de que cada enunciado tem autor e destinatário.

Segundo Bakhtin, o querer-dizer do locutor se realiza acima de tudo na escolha de um gênero do discurso. Essa escolha é determinada em função da especificidade de uma dada esfera da comunicação verbal, das necessidades de uma temática (do objeto do sentido), do conjunto constituído dos parceiros, etc. Depois disso, o intuito discursivo do locutor, sem que este renuncie à sua individualidade e à sua subjetividade, adapta-se e ajusta-se ao gênero escolhido, compõe-se e desenvolve-se na forma do gênero determinado. (p.301)

Para discutir a relação estilo individual e estilo de gênero, apresentamos alguns resultados das análises comparativas já realizadas (Fiad, 2003) sobre as escritas dos dois sujeitos com o objetivo de mostrar que L.M. e M.L., visando produzir determinados efeitos de sentido (humor em um caso e ironia/preocupação social em 
outro) escolhem determinados gêneros discursivos tendo em vista possibilidades neles presentes.

Defendemos o ponto de vista de que as tendências estilísticas presentes nas escritas dos dois sujeitos se manifestam preferencialmente em alguns gêneros discursivos que seriam, de uma certa maneira, mais propícios ao querer-dizer de cada escrevente. Esses, por outro lado, são gêneros com os quais as escreventes adquirem uma maior familiaridade durante seu processo de aquisição de escrita e, conseqüentemente, são mais explorados quanto aos seus recursos expressivos.

Durante suas histórias de escrita, cada escrevente vai se apropriando de gêneros que possibilitam a manifestação de seu estilo individual.

No caso da escrita de L.M., as análises apontam que, desde seus textos iniciais, há a construção de um efeito de humor, resultante da exploração de certas estratégias, manifestadas na escrita de alguns gêneros discursivos: poesias, relatos do cotidiano e narrativas de ficção. Os gêneros explorados por L.M. podem ser considerados como propícios às manifestações do estilo individual. Bakhtin mesmo diz que os mais propícios a essas manifestações são os gêneros literários. Sem pretender dizer que os textos de L.M. são literários (já que essa é outra discussão), podemos aproximá-los desses justamente pela flexibilidade presente em ambos.

Continuando o percurso de L.M., pode-se observar que, em sua produção escrita do ensino médio são encontrados gêneros diversos, como contos curtos, histórias policiais, crônicas, diários fictícios, cartas, ensaios argumentativos, editoriais, discurso de político. Alguns desses gêneros são marcados, em sua textualidade (ou estrutura composicional, segundo Bakhtin), pela narratividade. A tendência de construir textos bem humorados e engraçados permanece principalmente nesses últimos (contos, diários, cartas informais).

No entanto, é possível encontrar algumas escritas de L.M. em que ela parece deixar "escapar" o humor em gêneros onde essa característica pode ser considerada, no mínimo, inesperada. É o que ocorre em alguns textos produzidos para a disciplina "Estudos Sociais" - gênero informativo - que revelam, principalmente através de algumas escolhas lexicais, a mesma tendência estilística presente nos gêneros já mencionados. Como exemplo dessas escritas, citamos algumas produções da $4^{a}$ série do ensino fundamental:

Quando chegavam na fazenda [os imigrantes] eram levados até sua casa (velha caindo aos pedacos).

(Quando) saia o pagamento saia muito pouco, porque o fazendeiro fazia umas continhas errada aqui ali, ai o pagamento saia bem pouco, e de tanta raiva o imigrante ate matava o fazendeiro.

O tratado de Tordesilhas foi uma divisão que o papa fez entre a Espanha e Portugal, dividiram o Brasil com uma linha imaginaria, mas Portugal foi empurrando a Espanha e a Espanha só ficou com um tiquinho do Brasil. (oeste da Espanha e leste de Portugal)

As escritas de M.L., por sua vez, revelam, desde cedo, o trabalho para produzir nonsense, seguido da exploração da ironia. Essa ironia, em suas escritas posteriores, vai se manifestar especialmente em temas que privilegiem uma temática político-social. Os 
gêneros em que esse trabalho estilístico é preferencialmente desenvolvido por M.L. são: relatos, narrativas, poemas (ou embriões) e embriões de textos expositivos, cartas, panfletos, histórias em quadrinhos e textos dissertativos.

A exploração do nonsense, particularmente, se dá através de gêneros que permitem a manifestação da individualidade justamente por serem mais flexíveis. Quanto à ironia, quando começa a ser explorada nos textos de M.L. em relação à temática político-social, manifesta-se preferencialmente em gêneros que propiciam a construção de argumentos e a defesa mais explícita de um ponto de vista.

A preferência por um gênero não deve ser entendida como um abandono de outros gêneros onde a manifestação do estilo individual também pode ser observada. Mesmo em um momento de sua história de escrita em que M.L. já vem trabalhando gêneros que privilegiam a argumentação explícita - o que favorece a pretendida discussão de temáticas sociais - é possível verificar a retomada de um gênero mais freqüente no início de sua escolarização, onde há a exploração do efeito de nonsense. Isso pode ser observado em narrativas produzidas na $7^{\mathrm{a}}$ série, nas quais fica clara a preocupação com uma crítica a questões sociais.

Apresentamos, a seguir, exemplo de um texto narrativo produzido na $7^{\mathrm{a}}$ série, em situação escolar, que ilustra a exploração da temática apontada:

A torre

Terra, ano 2587, dia 23/09, hora 14:23. Há exatamente dez anos, completos hoje, houve a tão esperada "guerra, mas ao contrário do que se pensava os conflitos não acabariam quando a última bomba atômica caísse. Na verdade, a partir daí se iniciariam as maiores e mais devastadores conflitos... A guerra havia acabado com $75 \%$ dos humanos, mas a guerra não havia destruído "apenas" as cidades, as vilas e as vidas... Na verdade a guerra havia destruído toda uma sociedade, todos seus padrões, todo seu conhecimento. Agora a terra era um mundo hostil onde só sobreviviam os mais fortes, havia acabado a instituição do casamento, o amor, e até mesmo o ódio, agora as pessoas se comportavam como animais, que simplesmente ignoravam a presença de seres similares.

Eu tenho hoje quinze anos e as vagas lembranças que eu tenho da velha sociedade de nada me ajudam, pois eu tinha apenas cinco anos quando tudo explodiu. Eu estava lá, brincando na torre que ficava na época a alguns metros de casa, quando de repente, por de trás das pedras, vi surgir aquela estranha nuvem, eu logo corri para o alto da torre, onde vi tudo acabar... O tempo passa, e a torre começa a ser o único marco no deserto que é a minha vida... No alto da torre existem alguns livros que estão lá há várias gerações, deles retiro meu conhecimento, é entorno deles e da minha torre que roda a minha vida solitária. Mas uma noite, eu estava no topo da minha torre a ler e a comer alguns "animais das pedras" quando ouvi passos distantes... fiquei com medo, poderia ser algum homem mais forte, que com certeza mal me comeria, me usaria... Logo corri a me esconder, e comecei a observar a criatura por um furo na parede. Quando ele começou a se aproximar percebi que era um rapaz, jovem ainda, moreno e bastante conservado fisicamente. Trazia uma estranha sacola, com a qual balançava o tempo todo, chegou cada vez mais perto até que se sentou embaixo da torre. Não sei porque, mas ele me parecia ser inofensivo, pelo menos era diferente dos bárbaros que eu havia visto até agora... Foi aí que eu me dei conta que havia deixado meu "pano" lá embaixo. Como fazia frio precisava descer para pegá-lo. Desci, peguei, ele continuou lá a me observar com seus olhos brilhantes... O tempo passa, e ele continua a viver em baixo da torre, sempre a me observar, mas nunca me dirigia uma só palavra... Numa tarde saí para pegar água no "poço" para beber de noite, voltei e tive uma surpresa! Ele não estava mais lá! De repente senti um sentimento, uma coisa muito estranha, é como se eu estivesse triste por ele ter ido... subi degrau por degrau pensando nele e quando cheguei no topo da torre tive a maior surpresa da minha vida! Ele estava lá, lendo meus 
livros! Ele, sem se mover, assustado como eu, disse: - interessantes esses poemas !... Meu deus, ele sabia ler, sabia até o que era um poema! Fiquei tão estarrecida que comecei a falar com ele, a contar-lhe a respeito da minha vida da minha torre... era incrível, passei a noite toda a conversar, no início idéias confusas, diálogos desorganizados, mas no fim vi que ele lia, escrevia, vinha do norte e que também tinha suas idéias sobre a sociedade. Era incrível, pela primeira vez eu me senti feliz... Dali pra frente ele passou a compartilhar a minha torre, alguns anos mais tarde tivemos um filho, com o qual conversamos muito... Talvez aquele fosse o início de uma nova sociedade.

Pode-se dizer que, ao explorar esse viés em um gênero constituído basicamente por uma estrutura textual do tipo narração, a escrevente constrói também uma argumentação, desta vez mais sutil, sem a explicitude de argumentos que necessariamente está presente em textos do gênero dissertativo. Estes, por sua vez, passam a ser cada vez mais freqüentes na escrita de M.L., o que pode ser explicado não só pela escolarização - que privilegia esse gênero nas séries mais avançadas - mas também por sua preferência pela temática social, o que se manifesta ainda em sua escolha pelo curso universitário de História.

A análise dos dois percursos de escrita mostra a tendência estilística presente nos textos de cada sujeito, sendo que uma das facetas dos estilos individuais aqui delineados caracteriza-se pela escolha do gênero do discurso que possibilita a realização do querer-dizer de cada um. É possível afirmar que cada escrevente vai, no decorrer de suas escritas, manifestando preferência por alguns gêneros, que serão aqueles mais propícios à realização de seus intuitos discursivos, tendo em vista a flexibilidade ou maleabilidade dos gêneros. $O$ contato com esses gêneros - que passam a ser os mais freqüentes nas escritas desses sujeitos - vai sendo mais intenso e a exploração dos recursos lingüísticos próprios de cada gênero vai sendo maior e, provavelmente, mais consciente na sua história de escrita. Embora essa exploração dos recursos ainda mereça ser analisada mais cuidadosamente, é possível perceber que o mesmo gênero vai sendo mais trabalhado conforme a maturidade dos escreventes.

Também fica claro que a preferência por um gênero vai se constituindo durante um período da história de escrita, ou seja, é uma escolha resultante de experiências de escritas e de leituras vividas pelo sujeito.

Ao lado dessas preferências, é possível perceber a manifestação do estilo individual em outros gêneros que não seriam os mais propícios para essa manifestação devido às suas características ou, segundo Bakhtin, devido aos estilos que lhe são próprios. Essas aparentes contradições servem para confirmar o caráter maleável e flexível dos gêneros, mesmo daqueles que podem ser considerados menos flexíveis. Mostram também a flexibilidade dos estilos individuais nas escolhas dos gêneros, já que não há uma escolha fixa e imutável, mas um trabalho constante de novas buscas por parte dos sujeitos, em suas escritas.

\section{$\overline{\text { BIBLIOGRAFIA }}$}

ABAURRE, M.B.M. (1996). Os estudos Lingüísticos e a aquisição da escrita. Em: M.F.P. Castro (org.), O método e o dado no estudo da linguagem. Campinas: Editora da Unicamp. 
(1999a). Horizontes e limites de um programa de investigação em aquisição da escrita. Em: R.R. Lamprecht (org.), Aquisição da linguagem: questões e análises. Porto Alegre: EDIPUCRS.

(1999b). A emergência do estilo: as marcas de construção de autoria em textos representativos da aquisição da linguagem de um mesmo sujeito, da pré-escola ao segundo grau. Relatório de Pesquisa. CNPq.

(2001). A emergência do estilo: as marcas de construção de autoria em diferentes gêneros discursivos. Relatório de Pesquisa. CNPq.

. (2003). A emergência do estilo: o percurso de construção da ironia. Em: ACTAS-I do VIII Simposio Internacional de Comunicacion Social. Santiago de Cuba: Centro de Lingüística Aplicada/Ministerio de Ciencia, Tecnología y Medio Ambiente.

ABAURRE, M.B.M.; FIAD, R.S.; MAYRINK-SABINSON, M.L.T. \& GERALDI, J.W. (1995). Considerações sobre a utilização de um paradigma indiciário na análise de episódios de refacção textual. Em: Trabalhos de Lingüística Aplicada, (25). Campinas: IEL/ UNICAMP

ABAURRE, M.B.M.; FIAD, R.S. \& MAYRINK-SABINSON, M.L.T. (1997). Cenas de Aquisição da Escrita. O sujeito e o trabalho com o texto. Campinas, S.P.: ALB/Editora Mercado de Letras.

BAKHTIN, M. (1992) [1952-1953]. Os gêneros do discurso. Estética da criação verbal. São Paulo: Martins Fontes.

FIAD, R.S. (2003). Diferentes estilos no exercício de diferentes gêneros do discurso. Em: ACTAS-I do VIII Simposio Internacional de Comunicacion Social. Santiago de Cuba: Centro de Lingüística Aplicada/Ministerio de Ciencia, Tecnología y Medio Ambiente.

FRANCHI, C. (1977). Linguagem: atividade constitutiva. Em: Almanaque, (5). São Paulo: Brasiliense. . (1987). Criatividade e gramática. Em: Trabalhos em Lingüística Aplicada, (9). Campinas: IEL/ UNICAMP.

GINZBURG, C. (1986). Mitti Emblemi Spie: Morfologia e Storia. Torino: Einaudi. Tradução Brasileira: Mitos Emblemas Sinais: Morfologia e História. F. Carotti (trad.). São Paulo: Companhia das Letras

GRANGER, G.G. (1968). Filosofia do Estilo. São Paulo: Perspectiva/USP. (Trad. De Essai d'une Philosophie du Style).

MAYRINK-SABINSON, M.L.T. (1993). Indícios de individualidade na escrita inicial da criança. Estudos Lingüísticos XXII. Ribeirão Preto, SP..

. (2000). Fazendo humor no texto: a emergência do estilo a partir da análise de um corpus longitudinal em aquisição da escrita. Em: Trabalhos em Lingüística Aplicada, (36), Campinas, Unicamp.

. (2002). A emergência do estilo: construindo o humor no texto. Inédito.

(2003). Considerações sobre a emergência de um estilo individual: construindo o humor no texto. Em: ACTAS-I do VIII Simposio Internacional de Comunicacion Social. Santiago de Cuba: Centro de Lingüística Aplicada/Ministerio de Ciencia, Tecnología y Medio Ambiente.

POSSENTI, S. (1988). Discurso, estilo e Subjetividade. São Paulo: Martins Fontes. . (2001). Enunciação, autoria e estilo. Revista da FAEEBA 15. Salvador, BA. 